\title{
El impacto de la migración en el crecimiento poblacional del Estado de México
}

\author{
Alfonso Mejía-Modesto, María Viridiana Sosa-Márquez y \\ Eduardo Andrés Sandoval-Forero
}

\author{
Centro de Investigación y Estudios Avanzados de la Población de la \\ Universidad Autónoma del Estado de México
}

Resumen

El Estado de México en las últimas décadas presenta un importante crecimiento poblacional. De tal manera, consideramos relevante poder indagar sobre cuál de los componentes de la ecuación poblacional — fecundidad, mortalidad y migración - es la que juega el papel más importante en este incremento. Las diferencias municipales esconden grandes cambios y diferencias, más aún en el Estado de México que por sus dimensiones geográficas y características demográficas resulta sumamente diverso. De manera que este artículo surge de dos preguntas básicas: ¿Cuándo va a dejar de crecer aceleradamente la población del Estado de México? ¿Cuál ha sido el impacto de la migración? Los hallazgos principales muestran que el crecimiento de los municipios que forman parte de las dos zonas metropolitanas del Estado de México y Toluca y en los últimos años se explican principalmente por procesos de inmigración de población adulta. Además de que el crecimiento más acelerado corresponde a los municipios que forman el segundo o tercer contorno de las zonas metropolitanas, todo esto incide en el crecimiento del nuevo ejército industrial de reserva metropolitano y megalopolitano.

Palabras clave: Crecimiento poblacional, mancha urbana, municipios metropolitanos, ejército industrial de reserva, Estado de México.

\section{Abstract}

The impact of migration on the population growth of the State of Mexico

The State of Mexico, in last decades shows an important demographic growth. In such a way, we consider it relevant to be able to inquire about which of the components of the population equation - fertility, mortality and migration - plays the most important role in this increase. In this sense, it is important to be able to investigate the municipal differences that conceal great changes and differences, even more so in the State of Mexico, which by its geographical dimensions and demographic characteristics is extremely diverse. So this article comes from two basic questions: When will the population of the State of Mexico stop growing rapidly? What has been the impact of the migration? The main findings show that the growth of the municipalities that are part of the two metropolitan areas of the State of Mexico - Toluca and in recent years are mainly explained by immigration processes of adult population. In addition to the fact that the fastest growth corresponds to the municipalities that make up the second or third outline of the metropolitan areas, all this affects the growth of the new industrial army of metropolitan reserve, and even megapolitan.

Key words: Population growth, urban sprawl, metropolitan municipalities, industrial reserve army, State of Mexico. 


\section{INTRODUCCIÓN}

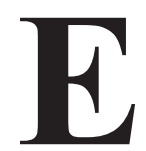

ste artículo surge de dos preguntas elementales ¿cuándo va a dejar de crecer aceleradamente la población del Estado de Méxi-

co? y ¿cuál ha sido el impacto de la migración en el crecimiento del Estado de México?

Estás preguntas surgen de la reflexión sobre el crecimiento de la población y su relación con el nivel de desarrollo en el Estado de México, utilizando datos que arrojan los Censos de Población y Vivienda y la Encuesta Intercensal 2015, levantados por el INEGI.

Este estudio tiene por objetivo hacer un análisis descriptivo y comparativo a nivel municipal, por lo que la fuente de información central utilizada son los Censos de Población y Vivienda, los Conteos de Población, y la Encuesta Intercensal 2015, levantados por el INEGI, todos con datos válidos a nivel municipal.

La hipótesis de este trabajo es que el crecimiento demográfico de la entidad, en los últimos años, se debe principalmente a la población inmigrante en edad adulta a municipios metropolitanos, y que el efecto social de este crecimiento es la expansión del nuevo ejército industrial de reserva.

La metodología de este documento es básicamente descriptiva y de comparación de información demográfica transversal. Para las comparaciones se utilizan los datos provenientes de censos de población y vivienda, los conteos, y las encuestas sociodemográficas. Entonces, la fuente de información central de este documento serán estos mismos, debido a que éstos permiten disponer de información a nivel municipal desde 1990 hasta el año 2010. Aunque nos centraremos de manera particular en la de la última Encuesta Intercensal de 2015.

El documento se organiza en cinco apartados: La evaluación del crecimiento demográfico y la medición de la migración. El crecimiento de la población total del Estado de México. La estructura de población comparada. La distribución poblacional por municipios comparada y Algunas reflexiones finales.

\section{LA EVALUACIÓN DEL CRECIMIENTO DEMOGRÁFICO, Y LA MEDICIÓN DE LA MIGRACIÓN}

En este apartado se presentan algunos muy breves elementos de la importancia de las mediciones de la población por medio de los censos de 
población de México. Además de algunos datos históricos demográficos a nivel nacional, así como la metodología utilizada durante el trabajo. Posteriormente se aborda el caso del Estado de México, por ser la población más numerosa y contrastante de todo el país, por su heterogeneidad en concentración de población y de desigualdad socioeconómica que se evidencia a través de los distintos estilos de vida en las localidades.

Frente al escenario poblacionista surgieron voces que llamaban la atención sobre los peligros de este acelerado crecimiento de la población. Quizá la más conocida fue la de Robert Malthus que en las últimas décadas del siglo XVIII, a principios del siglo XIX, llamó a la reducción del crecimiento de la población frente a un conflicto entre la velocidad de crecimiento de los bienes y la velocidad del crecimiento de la población.

Más de un siglo después, como un eco retardado surgieron nuevas voces de pensadores identificados como neomalthusianos, que tuvieron la posibilidad de ser escuchados por las figuras gobernantes más prominentes de la economía mundial. Estas voces al ser escuchadas dieron lugar a políticas de población controlistas. Las cuales se iniciaron de manera generalizada después de la Conferencia Mundial de Población de Bucarest de 1974 y orientaron las líneas generales de las políticas de desarrollo y crecimiento económico en todo el mundo. Las políticas controlistas de la población prometían el desarrollo para todas las naciones y el fin de la pobreza, promesas que no fueron cumplidas.

\section{Algunos antecedentes de la información demográfica en México y sus niveles}

Para fines del siglo XVIII, Alejandro Von Humboldt señalaba que la información del censo de 1793 mostraba una población total de México de 4'483,559 habitantes. No obstante, esta cifra era muy poco representativa de acuerdo al dinamismo de los hechos vitales (nacimientos y defunciones) registrados en esos años por el clero. Por lo que, de acuerdo a sus investigaciones, la población mexicana pudo haber alcanzado en el año de 1803 la cifra de 5.8 millones y en 1808 esta cifra se estimaba en 6.5 millones (Humboldt, 2002).

En el siguiente siglo, apenas diez años de iniciado el siglo XIX, estalló la guerra de independencia, que marca el inicio de constantes conflictos armados internos y externos en suelo nacional. A éstos se sumaron todas las epidemias, hambrunas, escasez de alimentos y otros fenómenos que atentaban contra el crecimiento sostenido de la población mexicana. Así en años posteriores al triunfo de los movimientos criollos independentistas 
le sucedieron la pérdida de Texas y otros territorios del norte del país. No se debe olvidar que la invasión norteamericana y otros acuerdos dieron lugar a la pérdida de más de la mitad del territorio nacional y obvio de la población nacional desligada del centro del país que estaba dispersa. También durante el siglo XIX ocurrió la invasión francesa y un importante número de levantamientos internos. Esto se asoció a un gran número de defunciones, y movimientos poblacionales en busca de la seguridad de las grandes ciudades, así como al no nacimiento de nuevos mexicanos en ese convulsionado siglo para la historia demográfica y política de México. En el contexto político-militar, de gran efervescencia, la población seguía sufriendo de manera muy notable el impacto de las enfermedades infecciosas transmisibles sumamente letales. Así, mientras se consumaba la independencia nacional la situación de la salud pública era profundamente grave. Estuvieron presentes durante siglos la viruela, el sarampión, el tifo, el paludismo, la tifoidea, las paperas, la influenza, entre otras (Bustamante et al., 1982).

En esos años también hubo una presencia importante de emigración de mexicanos. Durante los últimos años del siglo XIX e inicios del XX la emigración hacia Estados Unidos creció de manera considerable. En 1880 el número de mexicanos que emigraban a este país era de $68 \mathrm{mil}$ anualmente, en 1889 se alcanzó la cifra de 78 mil y para 1900 ésta fue de 103 milmigrantes. De hecho, en 1910, la oficina de Censos de los Estados Unidos registró 221915 mexicanos. Pero esta cifra crecía a 367510 personas consideradas de "raza mexicana", tomando en cuenta a los nacidos en Estados Unidos de padres mexicanos (McCaa, 2001).

La Revolución Mexicana produjo efectos de gran impacto en la dinámica poblacional. Por un lado redujo el número de nacimientos, y por el otro aumentó el número de muertes; así como también se incrementó la emigración.

En la Tabla 1 se puede observar un lento crecimiento de la población en las primeras décadas del siglo XX, el cual se aceleró entre 1950 y 1970, y para 1990 muestra una clara desaceleración. Pero la población no es inmóvil, y como se revisará más adelante, este crecimiento también ha estado acompañado de concentración, la que ha incidido particularmente en el Estado de México.

Hoy la importancia de medir el tamaño de la población es muy diferente a la de siglos anteriores. Los volúmenes mayores de población no se asocian al poderío militar o económico directamente. En la actualidad los censos de población y vivienda son mucho más ricos en las temáticas que 
abordan y en la información que aportan. Las otras formas de estimación del total de la población, como las proyecciones y las encuestas sociodemográficas, son también mucho más complejas, permitiendo no solo la medición de volúmenes sino también las historias sociodemográficas asociadas. Es por ello que los datos que miden a la población siguen siendo fundamentales para el diseño de políticas públicas en las entidades federativas, con la intención de que hagan posible las luchas por los derechos universales de los ciudadanos.

Tabla 1: Población censada en México, tasa de crecimiento intercensal y población estimada, $1900-2010$

\begin{tabular}{lrrrr}
\hline Año & Fecha censal & $\begin{array}{r}\text { Población } \\
\text { total censada }\end{array}$ & $\begin{array}{r}\text { Tasa anual de } \\
\text { crecimiento por ciento }\end{array}$ & $\begin{array}{r}\text { Población } \\
\text { total estimada }\end{array}$ \\
\hline 1900 & 28 de octubre & 13607259 & & \\
1910 & 27 de octubre & 15160369 & 1.1 & \\
1921 & 30 de noviembre & 14334780 & -0.5 & 17209033 \\
1930 & 15 de mayo & 16552644 & 1.7 & 19862666 \\
1940 & 6 de marzo & 19649162 & 1.8 & 23573012 \\
1950 & 6 de junio & 25779254 & 2.7 & 30918363 \\
1960 & 8 de junio & 34923129 & 3.1 & 41894382 \\
1970 & 28 de enero & 48225238 & 3.4 & 57839384 \\
1980 & 4 de junio & 66846833 & 3.2 & 80148034 \\
1990 & 12 de marzo & 81140922 & 2.0 & 97267654 \\
2000 & 14 de febrero & 97483412 & 1.0 & 100895811 \\
2005 & 19 de octubre & 103263388 & 1.4 & 107151011 \\
2010 & 12 de junio & 112336538 & 1.8 & 114255555 \\
\hline Funte & & & &
\end{tabular}

Asimismo, no se puede negar que los censos se han convertido también en herramientas para la mercadotecnia y el consumo. Con esta información se establecen las estimaciones sobre el número de consumidores potenciales, sus perfiles, y las estructuras etarias. Los censos permiten obtener los llamados demographics de un negocio, por ejemplo, para el establecimiento de un centro comercial o un desarrollo inmobiliario de gran tamaño, sólo por mencionar algunos. Así, los datos poblacionales son más usados por las instituciones financieras y las agencias de mercadotecnia, donde la población no es vista como personas sino como consumidores. Desde esta perspectiva la hiperconcentración de la población favorece el consumo de una economía basada en la acumulación de unos pocos, y el consumo creciente de todos. Pero cuando el consumidor pierde su capacidad de consumir es relegado y sustituido. Esto sucede con la población que pierde su 
empleo así la población crece más y a la par el número de pobres, mientras que la desigualdad socioeconómica se incrementa y la incertidumbre es la regla de nuestras vidas. Por lo tanto, no sólo es necesario observar volúmenes o tasas de crecimiento sino entender sus causas y sus efectos. Lo que puede ser entendido desde la crítica a la economía neoliberal o de riesgo como ha sido denominada por Ulrich Beck.

\section{La medición de la migración}

No es posible ignorar que la tecnología ha dado lugar a que los censos sean más accesibles. Hasta antes de 1990 había que esperar varios años para tener información censal a nivel general. Hoy en México contamos con toda una serie de datos demográficos muy importantes y con gran rapidez. A partir de 1990 contamos con registros libres, de acceso por internet, a nivel de entidad federativa, y en algunos casos, con representación municipal, de los censos, las encuestas en hogares. En particular, la Encuesta Intercensal 2015 tiene una disponibilidad de información que nos permite hacer investigaciones mucho más detalladas y pertinentes. No obstante, el tema de la migración tiene muchas dificultades para su medición precisa por distintas razones como por ejemplo: por omisión de declaración, por la forma de captación y su desagregación en las diversas fuentes de información, así como porque las personas no están obligadas legalmente a informar sobre sus movimientos residenciales al interior del país. La migración es un tema sumamente amplio y con diversas aristas. No obstante, en este artículo nos concentramos en la perspectiva de investigación demográfica. Desde esta perspectiva sólo hay dos opciones para medir la migración: el lugar de nacimiento o el lugar de residencia hace cinco años, y no los viajes continuos, los viajes de trabajo o las personas que viven en una ciudad pero trabajan en otra. Estas dos preguntas captan los grandes volúmenes pero no siempre toda la diversidad de movimientos poblacionales ni sus particularidades. Con la flexibilización del empleo y la subcontratación, es decir, la precarización del empleo en la economía del riesgo descrita por Ulrich Beck (1997), la movilidad se ha vuelto una exigencia.

También la ciudad de la sociedad del riesgo (Beck, 1997) ha dado las únicas oportunidades de alcanzar el crédito para una vivienda en las periferias de las zonas metropolitanas, lo cual en ocasiones significa el cambio de residencia y la movilidad intramunicipal o interestatal. Esto sucede de manera muy notable en el Estado de México, no obstante, esto no siempre se puede medir con precisión, pero la información que sí nos aportan los censos es una manifestación de los cambios de la población total, en las 
tasas de crecimiento muy aceleradas, lo cual se considera cuando las tasas son mayores a dos por ciento.

\section{El crecimiento de la población total del Estado de México}

Después del año 1975 se inició la desaceleración del crecimiento de la población a nivel nacional. En contra sentido, desde la década de 1970, la población del Estado de México ha tenido la etapa de crecimiento del volumen poblacional con niveles realmente grandes.

En 1960, de acuerdo al Censo de Población y Vivienda había 1.9 millones de habitantes. En 1990 este número alcanzó los 9.8 millones y para el 2015 fue de 16.2 millones. Esto es, 14.4 millones de diferencia en sólo 55 años. Por esto es fácil conocer muchas personas que han vivido - posiblemente sería mejor decir sufrido - el cambio y la masificación del Estado de México (véase Tabla 2).

La población del Estado de México continúa creciendo, si bien a velocidades menos aceleradas, crece de manera considerable. Cada día este crecimiento es en promedio de más de 500 personas. Como ya se mencionó antes, en tiempos remotos una población grande implicaba un gran poderío material, económico y una garantía para la guerra; además, una ciudad grande implicaba una gran experiencia de vida y de inigualables ventajas. Las primeras grandes ciudades permitían la movilidad social y daban la impresión de ser espacios de oportunidades ilimitadas tanto para los nacidos en ellas como para los inmigrantes. Ahora, de forma contraria, no sólo nos enfrentamos a la relación problemática entre el crecimiento de la población y el crecimiento de los bienes (la perspectiva malthusiana o neomathusiana) y a la distribución de esos bienes (la perspectiva socialista). Hoy el debate puede ser sobre la repartición de los riesgos (la perspectiva de la segunda modernidad), en donde por ejemplo el desarrollo de la ciencia y la tecnología propician la automatización y el crecimiento de un enorme ejercito industrial de reserva, es decir, una población que no tiene cabida en las actividades de la economía, y si acaso se logra incorporar en las actividades económicas esto es de manera parcial y principalmente en condiciones precarias y/o informales.

Así, la población del Estado de México ha mantenido su crecimiento, aunque a velocidades menos aceleradas. Entre 2005 y 2010 los datos de población muestran una ligerísima aceleración del crecimiento, que para el periodo 2010-2015 se ha reducido de manera apenas perceptible, en donde no debemos olvidar que estamos refiriéndonos a volúmenes de más de 15 millones de habitantes (véase Figura 1). 


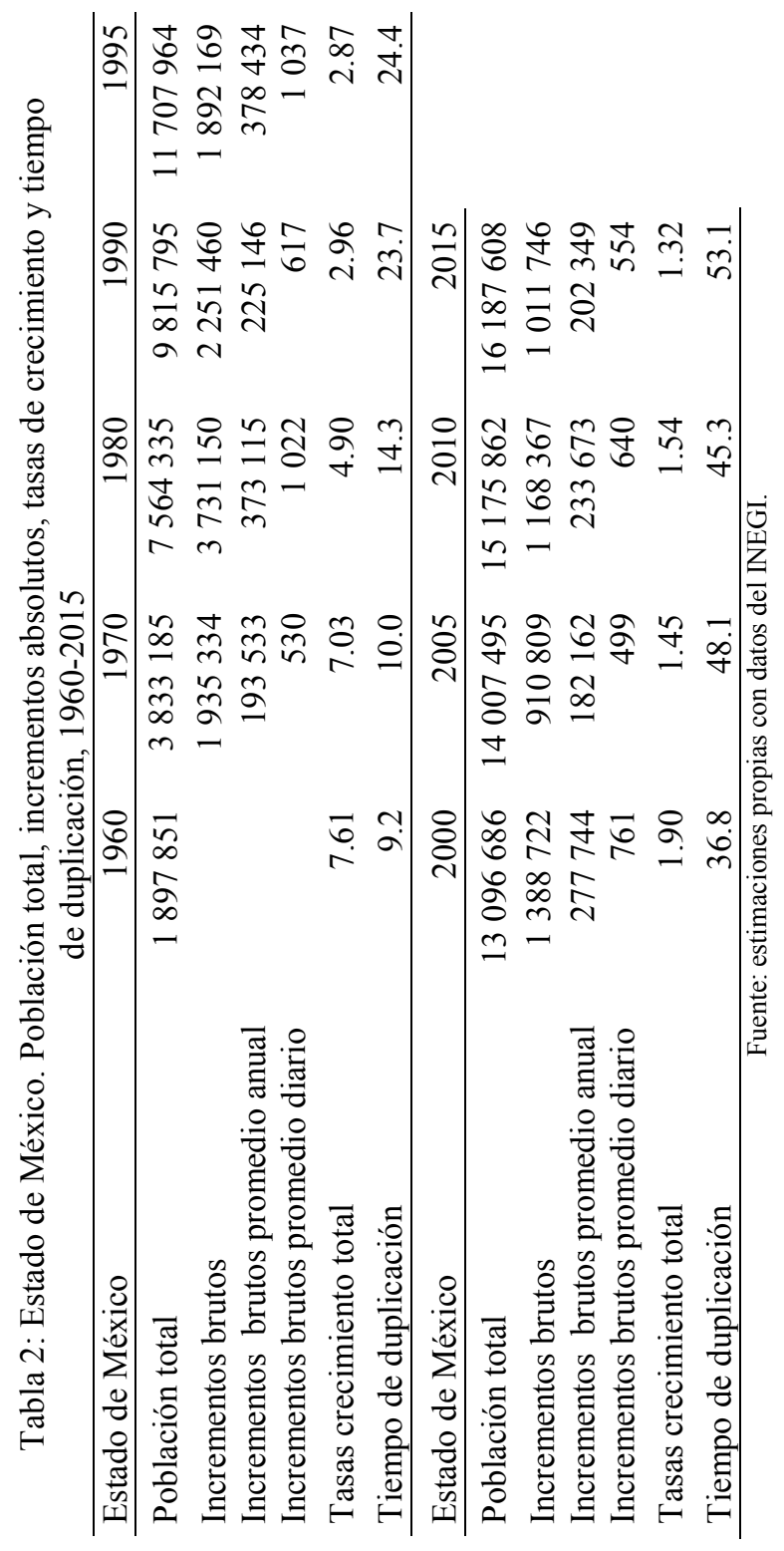


El impacto de la migración en el crecimiento poblacional del Estado de México / A. MEJÍA MODESTO et al.

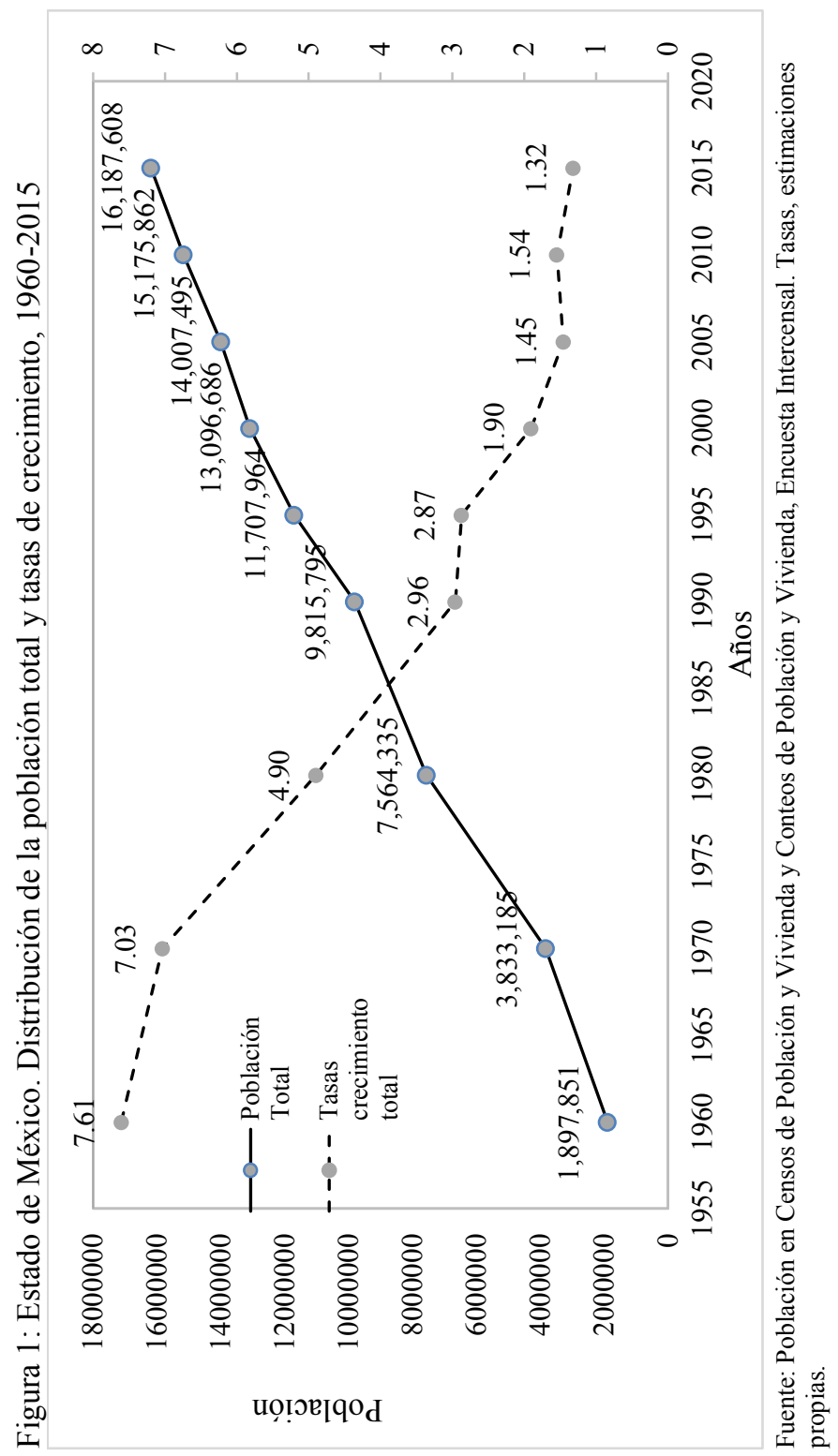




\section{LA ESTRUCTURA DE POBLACIÓN COMPARADA}

La estructura de población se representa en una pirámide que es un histograma de frecuencia basado en dos variables: edad y sexo. Cuando se presentan las pirámides de población en números absolutos es con el objetivo de dar cuenta de la dimensión en el cambio del volumen de la población. En este caso, se presenta la pirámide a nivel municipal en porcentajes, lo que permite comparar una población en diferentes momentos del tiempo. Habitualmente las transformaciones de la población se asocian a la teoría de la Transición Demográfica que supone tres etapas. En éstas se suponen poblaciones cerradas, es decir, sin inmigración o emigración. Por lo que, a nivel del Estado de México podríamos identificar el comportamiento de las pirámides con la Transición Demográfica hacia una población cuasiestacionaria (véase Figura 2).

En el caso de la comparación en números porcentuales de la pirámide por grupos quinquenales del Estado de México, entre 2010 y 2015, se muestra una tendencia muy clara de reducciones en los grupos menores al grupo de 35-39 años, mientras desde del grupo 40-44 años hay incrementos (véase Figura 3). Estos cambios se interpretan como cambios migratorios, o descensos de la fecundidad y no tanto como inercia demográfica debido a la velocidad con la que ocurren.

\section{LOS MUNICIPIOS COMPARADOS}

En el Estado de México, que por sus dimensiones geográficas y características demográficas resulta sumamente diverso, es muy común encontrar situaciones muy diferentes y en ocasiones hasta contrastantes. A continuación se presentan los volúmenes poblacionales de los 125 municipios que conforman la entidad hoy en día. Es importante notar que algunos de ellos son muy grandes, en términos de volumen demográfico, incluso mayores que algunas entidades del país. El municipio con mayor volumen de población es Ecatepec con 1.7 millones de habitantes, mientras que el de menor volumen es Zacazonapan, con poco más de cuatro mil habitantes. Es evidente que debido a la diversidad de esta entidad federativa se presentan diferencias importantes en las distintas dinámicas poblacionales municipales. De hecho, se combinan procesos muy complejos y resulta un tanto arbitrario o reduccionista utilizar sólo un valor para describir la dinámica demográfica en la entidad. Por ejemplo, la tasa de crecimiento de la población total a nivel estatal. 
El impacto de la migración en el crecimiento poblacional del Estado de México / A. MEJÍA MODESTO et al.

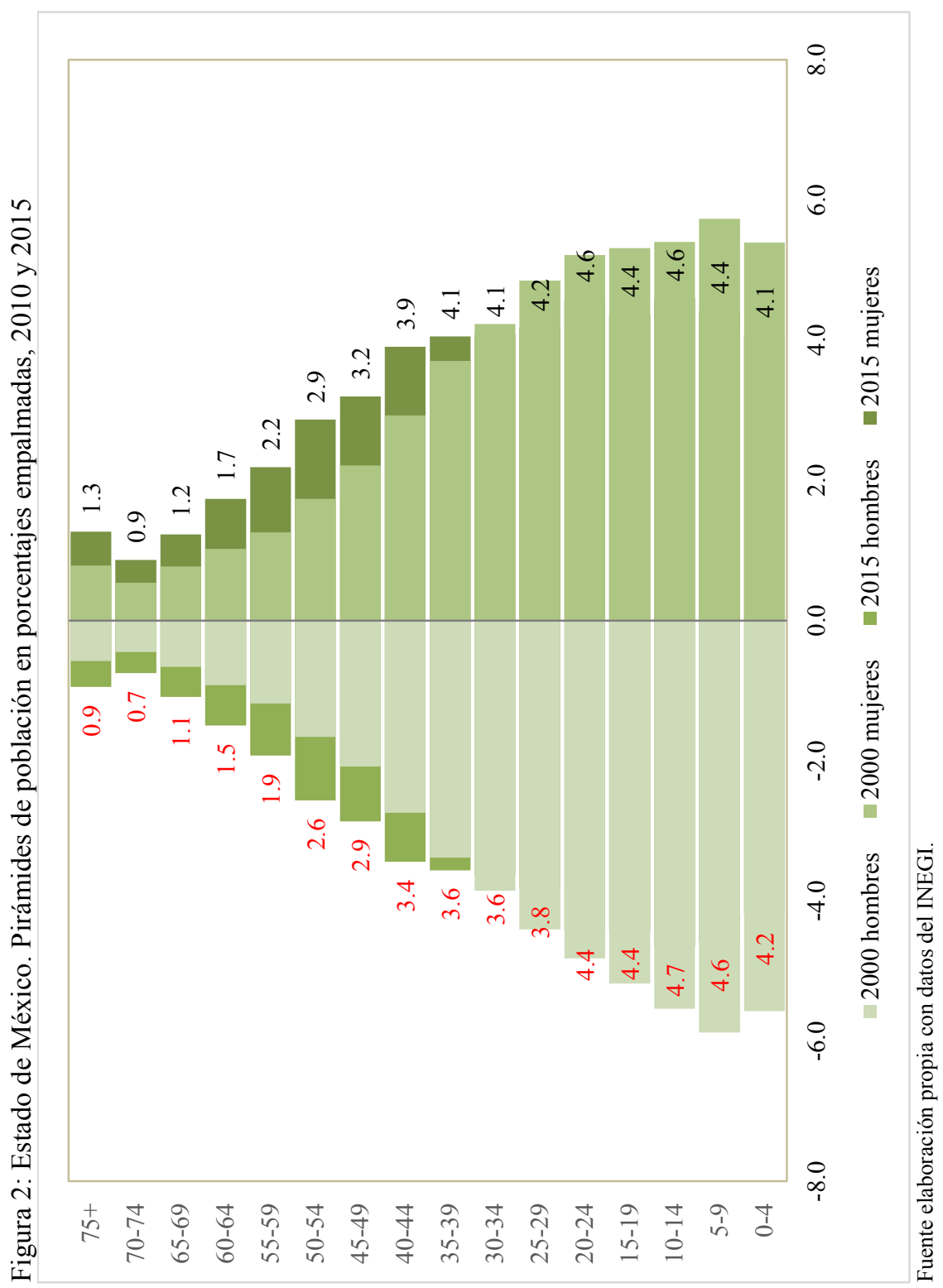




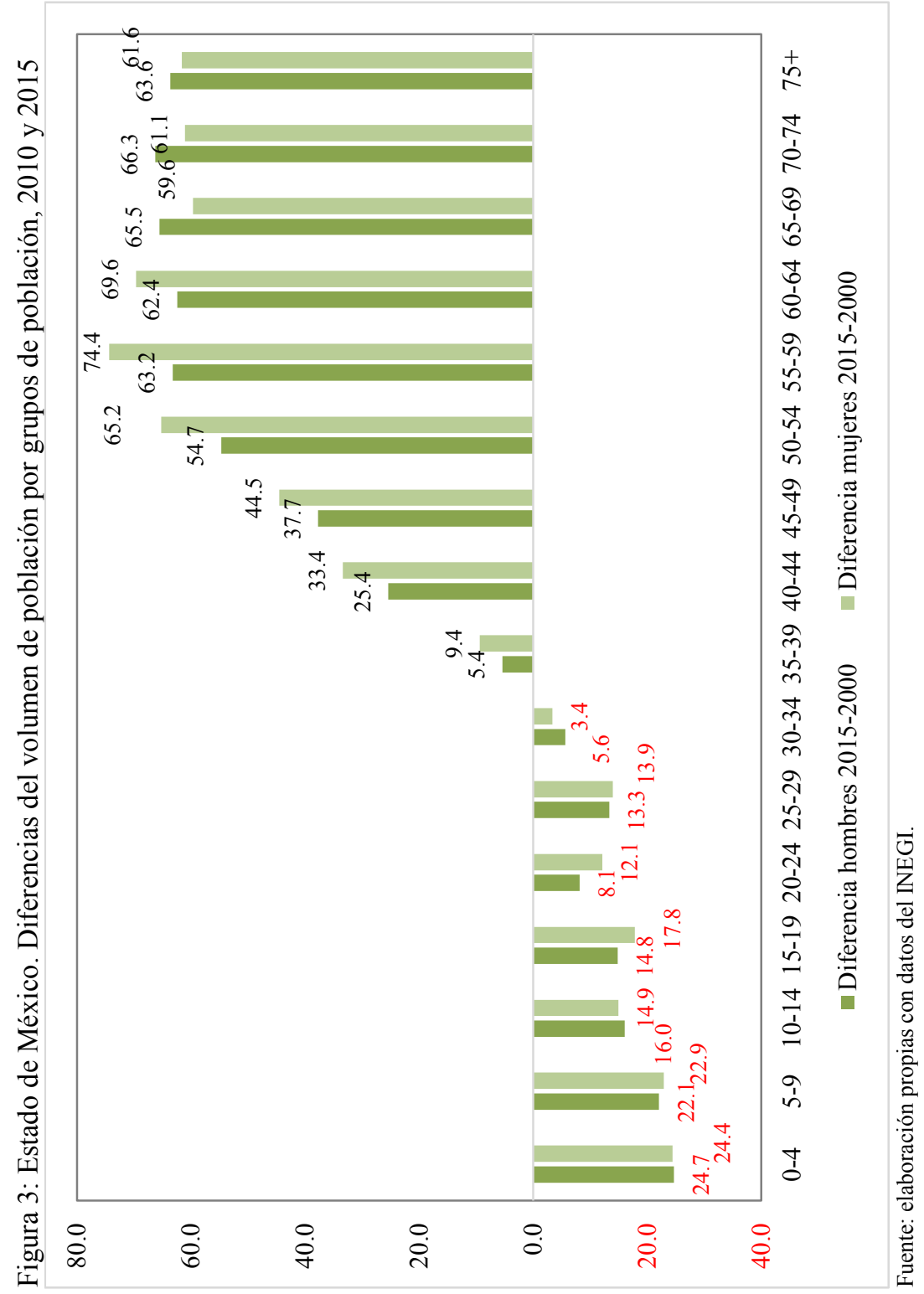


En la Tabla 3 se presentan las poblaciones de 2010 y 2015 con lo que se pueden estimar las porcentajes que representan del total (concentración poblacional), y por otro lado las diferencias porcentuales entre estos porcentajes. Lo que permite en primer momento identificar municipios con valores negativos en sus cambios poblacionales, en ocasiones con porcentajes de más de diez por ciento. Estas diferencias son sólo respecto del porcentaje que representa en la entidad. Es decir, el peso del municipio dentro de la entidad puede identificarse con la capacidad de cada municipio para consolidarse en espacio residencial.

Asimismo, los valores negativos sólo se pueden explicar por la emigración de la población, desde los municipios con localidades pequeñas y con pocas ofertas de empleo hacia zonas metropolitanas de mayor tamaño donde el mercado de trabajo se ve favorecido con la concentración, lo que representa para el empresario una ventaja.

En la Tabla 4 se presentan los porcentajes ordenados de menor a mayor sólo para 2015. Es muy claro que algunos municipios tienen un peso mínimo y por tanto cuando tienen importantes crecimientos el peso es marginal.

La Tabla 3 y la Tabla 4 nos permiten observar los cambios en las dimensiones poblacionales, pero también en su peso relativo (porcentajes). Los valores negativos implican un estancamiento del crecimiento de la población, que bien se podría explicar por la emigración de su población. Los mayores crecimientos, tanto en porcentajes como en valores absolutos, nos hablan de la concentración de los municipios metropolitanos donde hay contigüidad física, y donde sólo hay relación funcional, y que por lo regular hoy tienen volúmenes de población relativamente pequeños.

En la Tabla 4 a partir de los porcentajes acumulados se puede observar una gran concentración presente en algunos municipios, mientras que, por otro lado, en 69 municipios apenas alcanzan, de manera acumulada, poco más de diez por ciento de la población de la entidad.

El incremento total de la población en el Estado de México fue de 6.67 por ciento. Esta cifra no alcanza ni el crecimiento de trabajo en la economía formal ni el número de viviendas en condiciones adecuadas. Mientras que en sólo cinco municipios: Tlalnepantla de Baz, Naucalpan de Juárez, Toluca, Nezahualcóyotl, y Ecatepec de Morelos residen casi 32 por ciento de la población del Estado.

Destaca en la Tabla 5 el municipio de Nezahualcóyolt que muestra valores decrecientes en la población. El resto de los municipios que presentan disminuciones en valores absolutos corresponden a municipios rurales. 
Tabla 3a: Estado de México. Poblaciones total porcentual y diferencias entre porcentajes de población 2010 y 2015 .

\begin{tabular}{|c|c|c|c|c|c|}
\hline Municipio & $\begin{array}{r}\text { Población } \\
2010 \\
\end{array}$ & $\begin{array}{r}\text { Población } \\
2015 \\
\end{array}$ & $\begin{array}{r}\text { Porcentaje respecto } \\
\text { del total } 2010 \\
\end{array}$ & $\begin{array}{r}\text { Porcentaje respecto } \\
\text { del total } 2015 \\
\end{array}$ & $\begin{array}{r}\text { Diferencia porcentual } \\
2015-2010 \\
\end{array}$ \\
\hline Estado de México & 15175862 & 16187608 & 100.00 & 100.00 & \\
\hline Acambay & 60918 & 66034 & 0.40 & 0.41 & 1.62 \\
\hline Acolman & 136558 & 152506 & 0.90 & 0.94 & 4.70 \\
\hline Aculco & 44823 & 49026 & 0.30 & 0.30 & 2.54 \\
\hline Almoloya de Alquisiras & 14856 & 14846 & 0.10 & 0.09 & -6.31 \\
\hline Almoloya de Juárez & 147653 & 176237 & 0.97 & 1.09 & 11.90 \\
\hline Almoloya del Río & 10886 & 11126 & 0.07 & 0.07 & -4.18 \\
\hline Amanalco & 22868 & 24669 & 0.15 & 0.15 & 1.13 \\
\hline Amatepec & 26334 & 26610 & 0.17 & 0.16 & -5.27 \\
\hline Amecameca & 48421 & 50904 & 0.32 & 0.31 & -1.44 \\
\hline Apaxco & 27521 & 29347 & 0.18 & 0.18 & -0.03 \\
\hline Atenco & 56243 & 62392 & 0.37 & 0.39 & 4.00 \\
\hline Atizapán & 10299 & 11875 & 0.07 & 0.07 & 8.10 \\
\hline Atizapán de Zaragoza & 489937 & 523296 & 3.23 & 3.23 & 0.13 \\
\hline Atlacomulco & 93718 & 100675 & 0.62 & 0.62 & 0.71 \\
\hline Atlautla & 27663 & 30945 & 0.18 & 0.19 & 4.87 \\
\hline Axapusco & 25559 & 27709 & 0.17 & 0.17 & 1.64 \\
\hline Ayapango & 8864 & 9863 & 0.06 & 0.06 & 4.32 \\
\hline Calimaya & 47033 & 56574 & 0.31 & 0.35 & 12.77 \\
\hline Capulhuac & 34101 & 35495 & 0.22 & 0.22 & -2.42 \\
\hline Coacalco de Berriozábal & 278064 & 284462 & 1.83 & 1.76 & -4.09 \\
\hline Coatepec Harinas & 36174 & 39897 & 0.24 & 0.25 & 3.40 \\
\hline Cocotitlán & 12142 & 14414 & 0.08 & 0.09 & 11.29 \\
\hline Coyotepec & 39030 & 41810 & 0.26 & 0.26 & 0.43 \\
\hline Cuautitlán & 140059 & 149550 & 0.92 & 0.92 & 0.10 \\
\hline Chalco & 310130 & 343701 & 2.04 & 2.12 & 3.90 \\
\hline Chapa de Mota & 27551 & 28289 & 0.18 & 0.17 & -3.74 \\
\hline Chapultepec & 9676 & 11764 & 0.06 & 0.07 & 13.98 \\
\hline Chiautla & 26191 & 29159 & 0.17 & 0.18 & 4.37 \\
\hline Chicoloapan & 175053 & 204107 & 1.15 & 1.26 & 9.31 \\
\hline Chiconcuac & 22819 & 25543 & 0.15 & 0.16 & 4.94 \\
\hline Chimalhuacán & 614453 & 679811 & 4.05 & 4.20 & 3.72 \\
\hline Donato Guerra & 33455 & 34000 & 0.22 & 0.21 & -4.72 \\
\hline Ecatepec de Morelos & 1656107 & 1677678 & 10.91 & 10.36 & -5.03 \\
\hline Ecatzingo & 9369 & 9414 & 0.06 & 0.06 & -5.80 \\
\hline Huehuetoca & 100023 & 128486 & 0.66 & 0.79 & 20.43 \\
\hline Hueypoxtla & 39864 & 43784 & 0.26 & 0.27 & 2.97 \\
\hline Huixquilucan & 242167 & 267858 & 1.60 & 1.65 & 3.70 \\
\hline Isidro Fabela & 10308 & 11726 & 0.07 & 0.07 & 6.65 \\
\hline
\end{tabular}

Fuente: elaboración propias con datos del INEGI. 


\section{El impacto de la migración en el crecimiento poblacional del Estado de México / A. MEJÍA MODESTO et al.}

Tabla 3b: Poblaciones total porcentual y diferencias entre porcentajes de población 2010 y 2015.

Estado de México

\begin{tabular}{|c|c|c|c|c|c|}
\hline Municipio & $\begin{array}{r}\text { Población } \\
2010 \\
\end{array}$ & $\begin{array}{r}\text { Población } \\
2015 \\
\end{array}$ & $\begin{array}{r}\text { Porcentaje respecto } \\
\text { del total } 2010 \\
\end{array}$ & $\begin{array}{r}\text { Porcentaje respecto } \\
\text { del total } 2015 \\
\end{array}$ & $\begin{array}{r}\text { Diferencia porcentual } \\
2015-2010 \\
\end{array}$ \\
\hline Ixtapaluca & 467361 & 495563 & 3.08 & 3.06 & -0.59 \\
\hline Ixtapan de la Sal & 33541 & 35552 & 0.22 & 0.22 & -0.63 \\
\hline Ixtapan del Oro & 6629 & 6791 & 0.04 & 0.04 & -3.96 \\
\hline Ixtlahuaca & 141482 & 153184 & 0.93 & 0.95 & 1.50 \\
\hline Xalatlaco & 26865 & 29572 & 0.18 & 0.18 & 3.20 \\
\hline Jaltenco & 26328 & 27825 & 0.17 & 0.17 & -0.92 \\
\hline Jilotepec & 83755 & 87927 & 0.55 & 0.54 & -1.58 \\
\hline Jilotzingo & 17970 & 19013 & 0.12 & 0.12 & -0.81 \\
\hline Jiquipilco & 69031 & 74314 & 0.45 & 0.46 & 0.92 \\
\hline Jocotitlán & 61204 & 65291 & 0.40 & 0.40 & 0.01 \\
\hline Joquicingo & 12840 & 13857 & 0.08 & 0.09 & 1.18 \\
\hline Juchitepec & 23497 & 25436 & 0.15 & 0.16 & 1.49 \\
\hline Lerma & 134799 & 146654 & 0.89 & 0.91 & 1.99 \\
\hline Malinalco & 25624 & 27482 & 0.17 & 0.17 & 0.55 \\
\hline Melchor Ocampo & 50240 & 57152 & 0.33 & 0.35 & 6.65 \\
\hline Metepec & 214162 & 227827 & 1.41 & 1.41 & -0.27 \\
\hline Mexicaltzingo & 11712 & 12796 & 0.08 & 0.08 & 2.43 \\
\hline Morelos & 28426 & 29862 & 0.19 & 0.18 & -1.51 \\
\hline Naucalpan de Juárez & 833779 & 844219 & 5.49 & 5.22 & -5.08 \\
\hline Nezahualcóyotl & 1110565 & 1039867 & 7.32 & 6.42 & -12.22 \\
\hline Nextlalpan & 31691 & 39666 & 0.21 & 0.25 & 17.34 \\
\hline Nicolás Romero & 366602 & 410118 & 2.42 & 2.53 & 4.88 \\
\hline Nopaltepec & 8895 & 8960 & 0.06 & 0.06 & -5.57 \\
\hline Ocoyoacac & 61805 & 66190 & 0.41 & 0.41 & 0.40 \\
\hline Ocuilan & 31803 & 34485 & 0.21 & 0.21 & 1.66 \\
\hline El Oro & 34446 & 37343 & 0.23 & 0.23 & 1.63 \\
\hline Otumba & 34232 & 35274 & 0.23 & 0.22 & -3.40 \\
\hline Otzoloapan & 4864 & 3872 & 0.03 & 0.02 & -25.37 \\
\hline Otzolotepec & 78146 & 84519 & 0.51 & 0.52 & 1.40 \\
\hline Ozumba & 27207 & 29114 & 0.18 & 0.18 & 0.32 \\
\hline Papalotla & 4147 & 3963 & 0.03 & 0.02 & -10.41 \\
\hline $\mathrm{LaPaz}$ & 253845 & 293725 & 1.67 & 1.81 & 8.48 \\
\hline Polotitlán & 13002 & 13851 & 0.09 & 0.09 & -0.13 \\
\hline Rayón & 12748 & 13261 & 0.08 & 0.08 & -2.48 \\
\hline San Antonio la Isla & 22152 & 27230 & 0.15 & 0.17 & 15.24 \\
\hline San Felipe del Progreso & 121396 & 134143 & 0.80 & 0.83 & 3.59 \\
\hline $\begin{array}{l}\text { San Martín de las } \\
\text { Pirámides }\end{array}$ & 24851 & 26960 & 0.16 & 0.17 & 1.71 \\
\hline
\end{tabular}

Fuente: elaboración propias con datos del INEGI. 
Tabla 3c: Estado de México. Poblaciones total porcentual y diferencias entre porcentajes de población 2010 y 2015

\begin{tabular}{|c|c|c|c|c|c|}
\hline Municipio & $\begin{array}{r}\text { Población } \\
2010 \\
\end{array}$ & $\begin{array}{r}\text { Población } \\
2015 \\
\end{array}$ & $\begin{array}{r}\text { Porcentaje respecto } \\
\text { del total } 2010 \\
\end{array}$ & $\begin{array}{r}\text { Porcentaje respecto } \\
\text { del total } 2015 \\
\end{array}$ & $\begin{array}{r}\text { Diferencia porcentual } \\
2015-2010 \\
\end{array}$ \\
\hline San Mateo Atenco & 72579 & 75511 & 0.48 & 0.47 & -2.46 \\
\hline San Simón de Guerrero & 6272 & 6010 & 0.04 & 0.04 & -10.17 \\
\hline Santo Tomás & 9111 & 9682 & 0.06 & 0.06 & -0.37 \\
\hline Soyaniquilpan de Juárez & 11798 & 13290 & 0.08 & 0.08 & 5.61 \\
\hline Sultepec & 25809 & 26832 & 0.17 & 0.17 & -2.53 \\
\hline Tecámac & 364579 & 446008 & 2.40 & 2.76 & 14.69 \\
\hline Tejupilco & 71077 & 77799 & 0.47 & 0.48 & 2.62 \\
\hline Temamatla & 11206 & 12984 & 0.07 & 0.08 & 8.62 \\
\hline Temascalapa & 35987 & 38622 & 0.24 & 0.24 & 0.61 \\
\hline Temascalcingo & 62695 & 63721 & 0.41 & 0.39 & -4.72 \\
\hline Temascaltepec & 32870 & 31631 & 0.22 & 0.20 & -9.78 \\
\hline Temoaya & 90010 & 103834 & 0.59 & 0.64 & 8.15 \\
\hline Tenancingo & 90946 & 97891 & 0.60 & 0.60 & 0.91 \\
\hline Tenango del Aire & 10578 & 12470 & 0.07 & 0.08 & 10.52 \\
\hline Tenango del Valle & 77965 & 86380 & 0.51 & 0.53 & 3.87 \\
\hline Teoloyucán & 63115 & 66518 & 0.42 & 0.41 & -1.20 \\
\hline Teotihuacán & 53010 & 56993 & 0.35 & 0.35 & 0.79 \\
\hline Tepetlaoxtoc & 27944 & 30680 & 0.18 & 0.19 & 2.93 \\
\hline Tepetlixpa & 18327 & 19843 & 0.12 & 0.12 & 1.50 \\
\hline Tepotzotlán & 88559 & 94198 & 0.58 & 0.58 & -0.28 \\
\hline Tequixquiac & 33907 & 36902 & 0.22 & 0.23 & 2.03 \\
\hline Texcaltitlán & 17390 & 19206 & 0.11 & 0.12 & 3.54 \\
\hline Texcalyacac & 5111 & 5246 & 0.03 & 0.03 & -3.77 \\
\hline Texcoco & 235151 & 240749 & 1.55 & 1.49 & -4.02 \\
\hline Tezoyuca & 35199 & 41333 & 0.23 & 0.26 & 10.09 \\
\hline Tianguistenco & 70682 & 77147 & 0.47 & 0.48 & 2.32 \\
\hline Timilpan & 15391 & 15664 & 0.10 & 0.10 & -4.59 \\
\hline Tlalmanalco & 46130 & 47390 & 0.30 & 0.29 & -3.69 \\
\hline Tlalnepantla de Baz & 664225 & 700734 & 4.38 & 4.33 & -1.10 \\
\hline Tlatlaya & 32997 & 34937 & 0.22 & 0.22 & -0.74 \\
\hline Toluca & 819561 & 873536 & 5.40 & 5.40 & -0.08 \\
\hline Tonatico & 12099 & 12324 & 0.08 & 0.08 & -4.51 \\
\hline Tultepec & 131567 & 150182 & 0.87 & 0.93 & 7.01 \\
\hline Tultitlán & 486998 & 520557 & 3.21 & 3.22 & 0.21 \\
\hline Valle de Bravo & 61599 & 65703 & 0.41 & 0.41 & 0.00 \\
\hline Villa de Allende & 47709 & 52641 & 0.31 & 0.33 & 3.44 \\
\hline Villa del Carbón & 44881 & 47151 & 0.30 & 0.29 & -1.51 \\
\hline Villa Guerrero & 59991 & 67929 & 0.40 & 0.42 & 6.15 \\
\hline
\end{tabular}

Fuente: elaboración propias con datos del INEGI. 
El impacto de la migración en el crecimiento poblacional del Estado de México / A. MEJÍA MODESTO et al.

Tabla 3d: Estado de México. Poblaciones total porcentual y diferencias entre porcentajes de población 2010 y 2015

\begin{tabular}{lrrrrr}
\hline & Población & Población & Porcentaje respecto & Porcentaje respecto & Diferencia porcentual \\
Entidad Municipio & 2010 & 2015 & del total 2010 & del total 2015 & $2015-2010$ \\
\hline Villa Victoria & 94369 & 104612 & 0.62 & 0.65 & 3.93 \\
Xonacatlán & 46331 & 51646 & 0.31 & 0.32 & 4.50 \\
Zacazonapan & 4051 & 4137 & 0.03 & 0.03 & -4.26 \\
Zacualpan & 15121 & 14958 & 0.10 & 0.09 & -7.26 \\
Zinacantepec & 167759 & 188927 & 1.11 & 1.17 & 5.58 \\
Zumpahuacán & 16365 & 16927 & 0.11 & 0.10 & -3.03 \\
Zumpango & 159647 & 199069 & 1.05 & 1.23 & 16.90 \\
Cuautitlán Izcalli & 511675 & 531041 & 3.37 & 3.28 & -2.70 \\
Valle de Chalco Solidaridad & 357645 & 396157 & 2.36 & 2.45 & 3.85 \\
Luvianos & 27781 & 27860 & 0.18 & 0.17 & -5.98 \\
San José del Rincón & 91345 & 93878 & 0.60 & 0.58 & -3.65 \\
Tonanitla & 10216 & 9728 & 0.07 & 0.06 & -10.73 \\
\hline
\end{tabular}

Fuente: elaboración propias con datos del INEGI.

Estos resultados destacan algunos de los crecimientos más importantes en municipios de muy bajos niveles de desarrollo humano (véase CONAPO, 2016 y PNUD, 2015). También llaman la atención por su volumen y crecimiento exageradamente acelerado: Huehuetoca y Zumpango, en la zona norponiente; Tecámac, en el norte; La Paz, en el oriente; y todos los que conforman la Zona Metropolitana de Valle de México. En éstos la inmigración es la única explicación posible del crecimiento porque la otra sería el nivel de las tasas de fecundidad, pero éstas no muestran volúmenes tan grandes ni un crecimiento tan acelerado. Por ejemplo: si la población del Estado de México se incrementa en siete por ciento promedio anual se necesitaría que ocurrieran 1.1 millones de nacimientos en un año, para explicarlo, si dependiera únicamente de la fecundidad esto implicaría que cada año 25 por ciento de las mujeres en edad reproductiva tuvieran un hijo. Actualmente ocurren aproximadamente 300 mil nacimientos, esto quiere decir que menos de siete por ciento de las mujeres en edad reproductiva tienen un hijo cada año. Entonces, como vemos en el cuadro un incremento de cinco por ciento requeriría más de 800 mil nacimientos esto implica que 17 por ciento de las mujeres en edad reproductiva tendrían que tener un hijo. Esta población es la generación que aumentó de forma exorbitante por el ejército industrial de reserva, en municipios donde los puestos de trabajo son sumamente limitados (véase censos económicos). 
Tabla 4a: Estado de México. Porcentaje de población municipal 2015

\begin{tabular}{|c|c|c|}
\hline Municipio & $\begin{array}{r}\text { Porcentaje respecto } \\
\text { del total } 2015\end{array}$ & $\begin{array}{l}\text { Porcentaje acumulado } \\
\text { respecto del total } 2015\end{array}$ \\
\hline Otzoloapan & 0.02 & 0.02 \\
\hline Papalotla & 0.02 & 0.05 \\
\hline Zacazonapan & 0.03 & 0.07 \\
\hline Texcalyacac & 0.03 & 0.11 \\
\hline San Simón de Guerrero & 0.04 & 0.14 \\
\hline Ixtapan del Oro & 0.04 & 0.19 \\
\hline Nopaltepec & 0.06 & 0.24 \\
\hline Ecatzingo & 0.06 & 0.30 \\
\hline Santo Tomás & 0.06 & 0.36 \\
\hline Tonanitla & 0.06 & 0.42 \\
\hline Ayapango & 0.06 & 0.48 \\
\hline Almoloya del Río & 0.07 & 0.55 \\
\hline Isidro Fabela & 0.07 & 0.62 \\
\hline Chapultepec & 0.07 & 0.69 \\
\hline Atizapán & 0.07 & 0.77 \\
\hline Tonatico & 0.08 & 0.84 \\
\hline Tenango del Aire & 0.08 & 0.92 \\
\hline Mexicaltzingo & 0.08 & 1.00 \\
\hline Temamatla & 0.08 & 1.08 \\
\hline Rayón & 0.08 & 1.16 \\
\hline Soyaniquilpan de Juárez & 0.08 & 1.24 \\
\hline Polotitlán & 0.09 & 1.33 \\
\hline Joquicingo & 0.09 & 1.41 \\
\hline Cocotitlán & 0.09 & 1.50 \\
\hline Almoloya de Alquisiras & 0.09 & 1.60 \\
\hline Zacualpan & 0.09 & 1.69 \\
\hline Timilpan & 0.10 & 1.78 \\
\hline Zumpahuacán & 0.10 & 1.89 \\
\hline Jilotzingo & 0.12 & 2.01 \\
\hline Texcaltitlán & 0.12 & 2.13 \\
\hline Tepetlixpa & 0.12 & 2.25 \\
\hline Amanalco & 0.15 & 2.40 \\
\hline Juchitepec & 0.16 & 2.56 \\
\hline Chiconcuac & 0.16 & 2.72 \\
\hline Amatepec & 0.16 & 2.88 \\
\hline Sultepec & 0.17 & 3.05 \\
\hline San Martín de las Pirámides & 0.17 & 3.21 \\
\hline San Antonio la Isla & 0.17 & 3.38 \\
\hline
\end{tabular}

Fuente: elaboración propia con datos del INEGI. 
El impacto de la migración en el crecimiento poblacional del Estado de México / A. MEJÍA MODESTO et al.

Tabla 4b: Estado de México. Porcentaje de población municipal 2015

\begin{tabular}{|c|c|c|}
\hline Municipio & $\begin{array}{r}\text { Porcentaje respecto } \\
\text { del total } 2015 \\
\end{array}$ & $\begin{array}{l}\text { Porcentaje acumulado } \\
\text { respecto del total } 2015\end{array}$ \\
\hline Malinalco & 0.17 & 3.55 \\
\hline Axapusco & 0.17 & 3.72 \\
\hline Jaltenco & 0.17 & 3.89 \\
\hline Luvianos & 0.17 & 4.06 \\
\hline Chapa de Mota & 0.17 & 4.24 \\
\hline Ozumba & 0.18 & 4.42 \\
\hline Chiautla & 0.18 & 4.60 \\
\hline Apaxco & 0.18 & 4.78 \\
\hline Xalatlaco & 0.18 & 4.96 \\
\hline Morelos & 0.18 & 5.15 \\
\hline Tepetlaoxtoc & 0.19 & 5.34 \\
\hline Atlautla & 0.19 & 5.53 \\
\hline Temascaltepec & 0.20 & 5.72 \\
\hline Donato Guerra & 0.21 & 5.93 \\
\hline Ocuilan & 0.21 & 6.15 \\
\hline Tlatlaya & 0.22 & 6.36 \\
\hline Otumba & 0.22 & 6.58 \\
\hline Capulhuac & 0.22 & 6.80 \\
\hline Ixtapan de la Sal & 0.22 & 7.02 \\
\hline Tequixquiac & 0.23 & 7.25 \\
\hline El Oro & 0.23 & 7.48 \\
\hline Temascalapa & 0.24 & 7.72 \\
\hline Nextlalpan & 0.25 & 7.96 \\
\hline Coatepec Harinas & 0.25 & 8.21 \\
\hline Tezoyuca & 0.26 & 8.46 \\
\hline Coyotepec & 0.26 & 8.72 \\
\hline Hueypoxtla & 0.27 & 8.99 \\
\hline Villa del Carbón & 0.29 & 9.28 \\
\hline Tlalmanalco & 0.29 & 9.58 \\
\hline Aculco & 0.30 & 9.88 \\
\hline Amecameca & 0.31 & 10.19 \\
\hline Xonacatlán & 0.32 & 10.51 \\
\hline Villa de Allende & 0.33 & 10.84 \\
\hline Calimaya & 0.35 & 11.19 \\
\hline Teotihuacán & 0.35 & 11.54 \\
\hline Melchor Ocampo & 0.35 & 11.89 \\
\hline Atenco & 0.39 & 12.28 \\
\hline Temascalcingo & 0.39 & 12.67 \\
\hline
\end{tabular}

Fuente: elaboración propia con datos del INEGI. 
Tabla 4c: Estado de México. Porcentaje de población municipal 2015

\begin{tabular}{|c|c|c|}
\hline Municipio & $\begin{array}{r}\text { Porcentaje respecto del } \\
\text { total } 2015\end{array}$ & $\begin{array}{r}\text { Porcentaje acumulado } \\
\text { respecto del total } 2015\end{array}$ \\
\hline Jocotitlán & 0.40 & 13.08 \\
\hline Valle de Bravo & 0.41 & 13.48 \\
\hline Acambay & 0.41 & 13.89 \\
\hline Ocoyoacac & 0.41 & 14.30 \\
\hline Teoloyucán & 0.41 & 14.71 \\
\hline Villa Guerrero & 0.42 & 15.13 \\
\hline Jiquipilco & 0.46 & 15.59 \\
\hline San Mateo Atenco & 0.47 & 16.05 \\
\hline Tianguistenco & 0.48 & 16.53 \\
\hline Tejupilco & 0.48 & 17.01 \\
\hline Otzolotepec & 0.52 & 17.53 \\
\hline Tenango del Valle & 0.53 & 18.07 \\
\hline Jilotepec & 0.54 & 18.61 \\
\hline San José del Rincón & 0.58 & 19.19 \\
\hline Tepotzotlán & 0.58 & 19.77 \\
\hline $\begin{array}{l}\text { Tenancingo } \\
\text { Atlacomulco }\end{array}$ & $\begin{array}{l}0.60 \\
0.62\end{array}$ & $\begin{array}{l}20.38 \\
21.00\end{array}$ \\
\hline Temoaya & 0.64 & 21.64 \\
\hline Villa Victoria & 0.65 & 22.29 \\
\hline Huehuetoca & 0.79 & 23.08 \\
\hline San Felipe del Progreso & 0.83 & 23.91 \\
\hline Lerma & 0.91 & 24.81 \\
\hline Cuautitlán & 0.92 & 25.74 \\
\hline Tultepec & 0.93 & 26.67 \\
\hline Acolman & 0.94 & 27.61 \\
\hline Ixtlahuaca & 0.95 & 28.55 \\
\hline Almoloya de Juárez & 1.09 & 29.64 \\
\hline Zinacantepec & 1.17 & 30.81 \\
\hline Zumpango & 1.23 & 32.04 \\
\hline Chicoloapan & 1.26 & 33.30 \\
\hline Metepec & 1.41 & 34.71 \\
\hline Texcoco & 1.49 & 36.20 \\
\hline Huixquilucan & 1.65 & 37.85 \\
\hline Coacalco de Berriozábal & 1.76 & 39.61 \\
\hline La Paz & 1.81 & 41.42 \\
\hline Chalco & 2.12 & 43.55 \\
\hline Valle de Chalco Solidaridad & 2.45 & 45.99 \\
\hline Nicolás Romero & 2.53 & 48.53 \\
\hline Tecámac & 2.76 & 51.28 \\
\hline Ixtapaluca & 3.06 & 54.34 \\
\hline Tultitlán & 3.22 & 57.56 \\
\hline
\end{tabular}

Fuente: elaboración propia con datos del INEGI. 
Tabla 4d: Estado de México. Porcentaje de población municipal 2015

\begin{tabular}{lrr}
\hline & $\begin{array}{r}\text { Porcentaje respecto del } \\
\text { total } 2015 \text { ordenados de } \\
\text { menor a mayor }\end{array}$ & $\begin{array}{r}\text { Porcentaje acumulado } \\
\text { respecto del total 2015 }\end{array}$ \\
\hline Atizapán de Zaragoza & 3.23 & 60.79 \\
Cuautitlán Izcalli & 3.28 & 64.07 \\
Chimalhuacán & 4.20 & 68.27 \\
Tlalnepantla de Baz & 4.33 & 72.60 \\
Naucalpan de Juárez & 5.22 & 77.82 \\
Toluca & 5.40 & 83.21 \\
Nezahualcóyotl & 6.42 & 89.64 \\
Ecatepec de Morelos & 10.36 & 100.00 \\
Estado de México & 100.00 & \\
\hline
\end{tabular}

Fuente: elaboración propia con datos del INEGI.

Algunos de los crecimientos más importantes, pero en municipios de tamaño pequeño son: San Antonio la Isla, Chapultepec, Calimaya y Almoloya de Juárez, en el sur de la Zona Metropolitana del Valle de Toluca (véase Figura 4 y Tabla 6).

El crecimiento del ejército industrial de reserva debilita la posibilidad de mejorar los ingresos. Pero, como señala Hans Küng (2000: 236) "lo que garantiza a largo plazo mayor nivel de vida y paz social no son precisamente más altas prestaciones sociales del Estado a los ciudadanos, sino un crecimiento económico sostenido, más puestos de trabajo y mayores ingresos reales". Ello representa un enorme reto frente a una de las características de la globalización: la llamada flexibilización del mercado de trabajo, la cual es una forma de explotación mucho más radical a las clases sociales que, si bien forman parte del mercado laboral formal, sus formas de contratación no les permiten acceder a la protección del Estado. Esto es, las formas de contratación por honorarios profesionales, las microempresas, entre otras, no cuentan con ninguna protección al trabajador siendo éste el principal crecimiento económico de las metrópolis, la forma principal de encontrar empleo hoy en día. Asimismo, las ciudades dormitorio son cada vez una realidad más cotidiana para muchas de las personas. El vivir y trabajar a una gran distancia o bien ocupando mucho tiempo en el traslado es cada vez más común en la complejidad de la ciudad. Eso nos remite a la también llamada migración pendular. Es decir, las personas que viven en una ciudad pero trabajan en otra, por lo que van y vienen diariamente, esto puede cambiar, ya sea por un cambio de residencia o un cambio de empleo. 


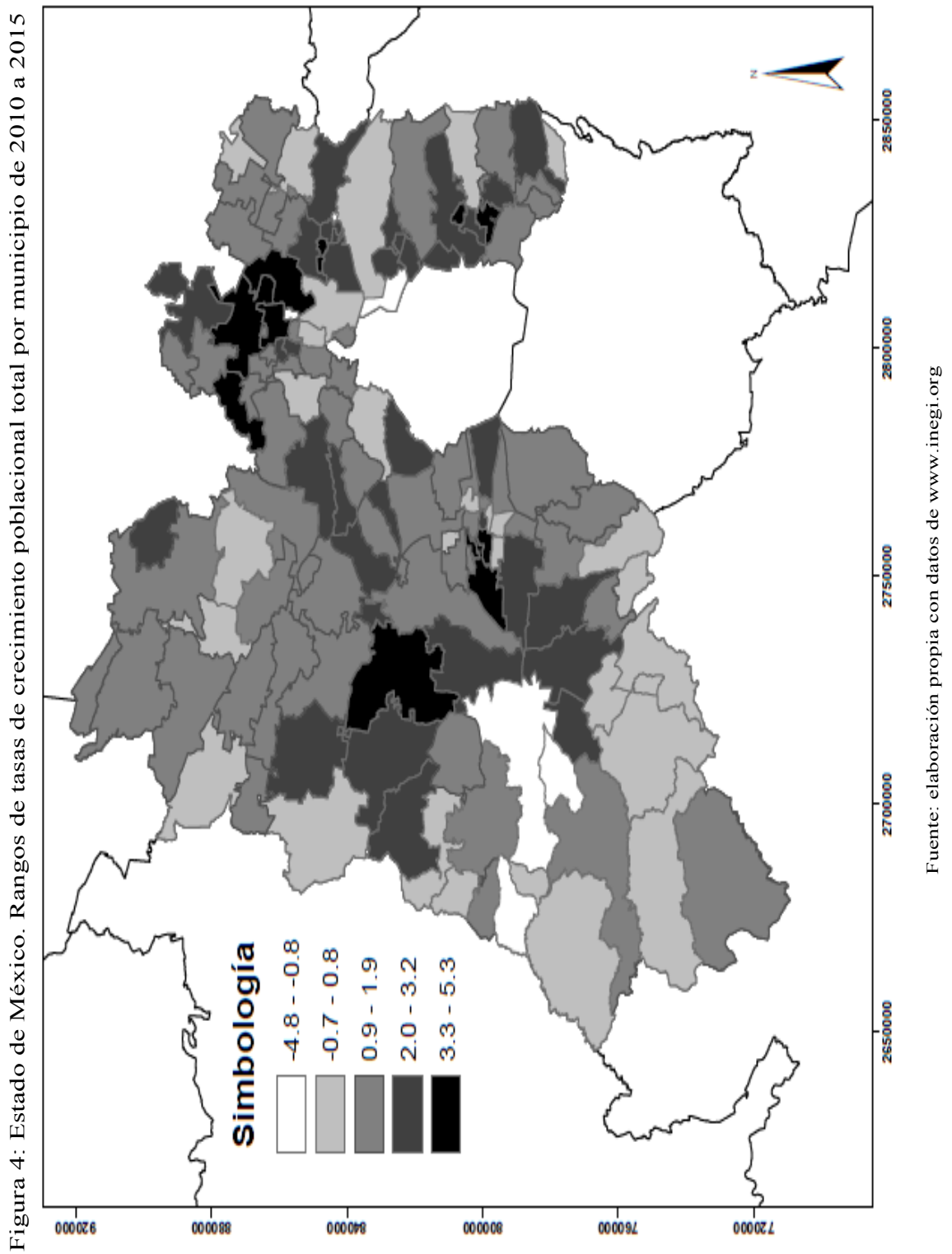


El impacto de la migración en el crecimiento poblacional del Estado de México / A. MEJÍA MODESTO et al.

Tabla 5a: Estado de México. Diferencia porcentual de la población relativa entre 2015 y 2010

\begin{tabular}{|c|c|}
\hline Municipio & Diferencia porcentual \\
\hline Otzoloapan & -25.37 \\
\hline Nezahualcóyotl & -12.22 \\
\hline Tonanitla & -10.73 \\
\hline Papalotla & -10.41 \\
\hline San Simón de Guerrero & -10.17 \\
\hline Temascaltepec & -9.78 \\
\hline Zacualpan & -7.26 \\
\hline Almoloya de Alquisiras & -6.31 \\
\hline Luvianos & -5.98 \\
\hline Ecatzingo & -5.80 \\
\hline Nopaltepec & -5.57 \\
\hline Amatepec & -5.27 \\
\hline Naucalpan de Juárez & -5.08 \\
\hline Ecatepec de Morelos & -5.03 \\
\hline Donato Guerra & -4.72 \\
\hline Temascalcingo & -4.72 \\
\hline Timilpan & -4.59 \\
\hline Tonatico & -4.51 \\
\hline Zacazonapan & -4.26 \\
\hline Almoloya del Río & -4.18 \\
\hline Coacalco de Berriozábal & -4.09 \\
\hline Texcoco & -4.02 \\
\hline Ixtapan del Oro & -3.96 \\
\hline Texcalyacac & -3.77 \\
\hline Chapa de Mota & -3.74 \\
\hline Tlalmanalco & -3.69 \\
\hline San José del Rincón & -3.65 \\
\hline Otumba & -3.40 \\
\hline Zumpahuacán & -3.03 \\
\hline Cuautitlán Izcalli & -2.70 \\
\hline Sultepec & -2.53 \\
\hline Rayón & -2.48 \\
\hline San Mateo Atenco & -2.46 \\
\hline Capulhuac & -2.42 \\
\hline Jilotepec & -1.58 \\
\hline Morelos & -1.51 \\
\hline Villa del Carbón & -1.51 \\
\hline Amecameca & -1.44 \\
\hline Teoloyucán & -1.20 \\
\hline Tlalnepantla de Baz & -1.10 \\
\hline
\end{tabular}

Fuente: elaboración propia con datos del INEGI. 
Tabla 5b: Estado de México. Diferencia porcentual de la población relativa entre 2015 y 2010

\begin{tabular}{|c|c|}
\hline Municipio & Diferencia porcentual \\
\hline Jaltenco & -0.92 \\
\hline Jilotzingo & -0.81 \\
\hline Tlatlaya & -0.74 \\
\hline Ixtapan de la Sal & -0.63 \\
\hline Ixtapaluca & -0.59 \\
\hline Santo Tomás & -0.37 \\
\hline Tepotzotlán & -0.28 \\
\hline Metepec & -0.27 \\
\hline Polotitlán & -0.13 \\
\hline Toluca & -0.08 \\
\hline Apaxco & -0.03 \\
\hline Valle de Bravo & 0.00 \\
\hline Jocotitlán & 0.01 \\
\hline Cuautitlán & 0.10 \\
\hline Atizapán de Zaragoza & 0.13 \\
\hline Tultitlán & 0.21 \\
\hline Ozumba & 0.32 \\
\hline Ocoyoacac & 0.40 \\
\hline Coyotepec & 0.43 \\
\hline Malinalco & 0.55 \\
\hline Temascalapa & 0.61 \\
\hline Atlacomulco & 0.71 \\
\hline Teotihuacán & 0.79 \\
\hline Tenancingo & 0.91 \\
\hline Jiquipilco & 0.92 \\
\hline Amanalco & 1.13 \\
\hline Joquicingo & 1.18 \\
\hline Otzolotepec & 1.40 \\
\hline Juchitepec & 1.49 \\
\hline Ixtlahuaca & 1.50 \\
\hline Tepetlixpa & 1.50 \\
\hline Acambay & 1.62 \\
\hline El Oro & 1.63 \\
\hline Axapusco & 1.64 \\
\hline Ocuilan & 1.66 \\
\hline San Martín de las Pirámides & 1.71 \\
\hline Lerma & 1.99 \\
\hline Tequixquiac & 2.03 \\
\hline Tianguistenco & 2.32 \\
\hline Mexicaltzingo & 2.43 \\
\hline
\end{tabular}

Fuente: elaboración propia con datos del INEGI. 
El impacto de la migración en el crecimiento poblacional del Estado de México / A. MEJÍA MODESTO et al.

Tabla 5c: Estado de México. Diferencia porcentual de la población relativa entre 2015 y 2010

\begin{tabular}{|c|c|}
\hline Municipio & Diferencia porcentual \\
\hline Aculco & 2.54 \\
\hline Tejupilco & 2.62 \\
\hline Tepetlaoxtoc & 2.93 \\
\hline Hueypoxtla & 2.97 \\
\hline Xalatlaco & 3.20 \\
\hline Coatepec Harinas & 3.40 \\
\hline Villa de Allende & 3.44 \\
\hline Texcaltitlán & 3.54 \\
\hline San Felipe del Progreso & 3.59 \\
\hline Huixquilucan & 3.70 \\
\hline Chimalhuacán & 3.72 \\
\hline Valle de Chalco Solidaridad & 3.85 \\
\hline Tenango del Valle & 3.87 \\
\hline Chalco & 3.90 \\
\hline Villa Victoria & 3.93 \\
\hline Atenco & 4.00 \\
\hline Ayapango & 4.32 \\
\hline Chiautla & 4.37 \\
\hline Xonacatlán & 4.50 \\
\hline Acolman & 4.70 \\
\hline Atlautla & 4.87 \\
\hline Nicolás Romero & 4.88 \\
\hline Chiconcuac & 4.94 \\
\hline Zinacantepec & 5.58 \\
\hline Soyaniquilpan de Juárez & 5.61 \\
\hline Villa Guerrero & 6.15 \\
\hline Isidro Fabela & 6.65 \\
\hline Melchor Ocampo & 6.65 \\
\hline Tultepec & 7.01 \\
\hline Atizapán & 8.10 \\
\hline Temoaya & 8.15 \\
\hline La Paz & 8.48 \\
\hline Temamatla & 8.62 \\
\hline Chicoloapan & 9.31 \\
\hline Tezoyuca & 10.09 \\
\hline Tenango del Aire & 10.52 \\
\hline Cocotitlán & 11.29 \\
\hline Almoloya de Juárez & 11.90 \\
\hline Calimaya & 12.77 \\
\hline Chapultepec & 13.98 \\
\hline
\end{tabular}

Fuente: elaboración propia con datos del INEGI. 
Tabla 5d: Estado de México. Diferencia porcentual de la población relativa entre 2015 y 2010

\begin{tabular}{lr}
\hline Municipio & Diferencia \\
\hline Tecámac & 14.69 \\
San Antonio la Isla & 15.24 \\
Zumpango & 16.90 \\
Nextlalpan & 17.34 \\
Huehuetoca & 20.43 \\
\hline
\end{tabular}

Fuente: elaboración propia con datos del INEGI.

\section{Algunas Reflexiones finales}

Con el crecimiento que se ha registrado en la entidad y con el crecimiento que nos espera, ya que como se señaló previamente los cambios demográficos no son nunca espectaculares, cabría hacerse dos preguntas: ¿Qué puede cambiar en términos de población? ¿Hacia dónde podríamos ir?

Podemos decir que se comprueba la hipótesis planteada que se basa en lo que encontramos con los datos de la Encuesta Intercensal 2015. Estos hallazgos implican repensar la dinámica demográfica en la entidad y las políticas demográficas implementadas o bien, y que puede ser más importante, es necesario reflexionar sobre las políticas públicas que se han dejado de implementar, las decisiones de política pública que inciden en este crecimiento desmedido. Como por ejemplo la autorización de conjuntos urbanos masivos, nuevas rutas e infraestructura de transporte que facilitan la expansión urbana.

La migración individual dificulta la conciliación entre la vida laboral y la familiar. Esto se vincula con la reducción y la postergación de la fecundidad pero también con la dificultad de tener mejores oportunidades para hacer distintas actividades en la vida. Es decir, tener una vida multidimensional, como una experiencia más plena y cercana al proyecto de vida elegido. Por su parte, la migración familiar rompe con las relaciones de la familia ampliada. Lo que puede dificultar el ejercicio del parentesco, bajo la idea tradicional del mismo. Por lo que las personas o las familias que migran ahora pueden crecer sin la presencia cotidiana de los abuelos, tíos y primos, entre otras.

Ahora bien, la flexibilidad laboral exige movilidad de empleos, desplazamientos y cambios de horarios. También reclama diplomas, títulos y actualizaciones continuas en la capacitación para el empleo. Las licenciaturas se han devaluado y ya no garantizan el abandono del desempleo. 
El impacto de la migración en el crecimiento poblacional del Estado de México / A. MEJÍA MODESTO et al.

Tabla 6a: Estado de México. Diferencia porcentual de población absoluta de 2015 a 2010

\begin{tabular}{|c|c|}
\hline Municipio & Diferencia porcentual \\
\hline Estado de México & 6.67 \\
\hline Otzoloapan & -20.39 \\
\hline Nezahualcóyotl & -6.37 \\
\hline Tonanitla & -4.78 \\
\hline Papalotla & -4.44 \\
\hline San Simón de Guerrero & -4.18 \\
\hline Temascaltepec & -3.77 \\
\hline Zacualpan & -1.08 \\
\hline Almoloya de Alquisiras & -0.07 \\
\hline Luvianos & 0.28 \\
\hline Ecatzingo & 0.48 \\
\hline Nopaltepec & 0.73 \\
\hline Amatepec & 1.05 \\
\hline Naucalpan de Juárez & 1.25 \\
\hline Ecatepec de Morelos & 1.30 \\
\hline Donato Guerra & 1.63 \\
\hline Temascalcingo & 1.64 \\
\hline Timilpan & 1.77 \\
\hline Tonatico & 1.86 \\
\hline Zacazonapan & 2.12 \\
\hline Almoloya del Río & 2.20 \\
\hline Coacalco de Berriozábal & 2.30 \\
\hline Texcoco & 2.38 \\
\hline Ixtapan del Oro & 2.44 \\
\hline Texcalyacac & 2.64 \\
\hline Chapa de Mota & 2.68 \\
\hline Tlalmanalco & 2.73 \\
\hline San José del Rincón & 2.77 \\
\hline Otumba & 3.04 \\
\hline Zumpahuacán & 3.43 \\
\hline Cuautitlán Izcalli & 3.78 \\
\hline Sultepec & 3.96 \\
\hline Rayón & 4.02 \\
\hline San Mateo Atenco & 4.04 \\
\hline Capulhuac & 4.09 \\
\hline Jilotepec & 4.98 \\
\hline Morelos & 5.05 \\
\hline Villa del Carbón & 5.06 \\
\hline Amecameca & 5.13 \\
\hline Teoloyucan & 5.39 \\
\hline
\end{tabular}

Fuente: elaboración propia con datos del INEGI. 
Tabla 6b: Estado de México. Diferencia porcentual de población absoluta de 2015 a 2010

\begin{tabular}{|c|c|}
\hline Municipio & Diferencia porcentual \\
\hline Tlalnepantla de Baz & 5.50 \\
\hline Jaltenco & 5.69 \\
\hline Jilotzingo & 5.80 \\
\hline Tlatlaya & 5.88 \\
\hline Ixtapan de la Sal & 6.00 \\
\hline Ixtapaluca & 6.03 \\
\hline Santo Tomás & 6.27 \\
\hline Tepotzotlán & 6.37 \\
\hline Metepec & 6.38 \\
\hline Polotitlán & 6.53 \\
\hline Toluca & 6.59 \\
\hline Apaxco & 6.63 \\
\hline Valle de Bravo & 6.66 \\
\hline Jocotitlán & 6.68 \\
\hline Cuautitlán & 6.78 \\
\hline Atizapán de Zaragoza & 6.81 \\
\hline Tultitlán & 6.89 \\
\hline Ozumba & 7.01 \\
\hline Ocoyoacac & 7.09 \\
\hline Coyotepec & 7.12 \\
\hline Malinalco & 7.25 \\
\hline Temascalapa & 7.32 \\
\hline Atlacomulco & 7.42 \\
\hline Teotihuacán & 7.51 \\
\hline Tenancingo & 7.64 \\
\hline Jiquipilco & 7.65 \\
\hline Amanalco & 7.88 \\
\hline Joquicingo & 7.92 \\
\hline Otzolotepec & 8.16 \\
\hline Juchitepec & 8.25 \\
\hline Ixtlahuaca & 8.27 \\
\hline Tepetlixpa & 8.27 \\
\hline Acambay & 8.40 \\
\hline El Oro & 8.41 \\
\hline Axapusco & 8.41 \\
\hline Ocuilan & 8.43 \\
\hline San Martín de las Pirámides & 8.49 \\
\hline Lerma & 8.79 \\
\hline Tequixquiac & 8.83 \\
\hline Tianguistenco & 9.15 \\
\hline
\end{tabular}

Fuente: elaboración propia con datos del INEGI. 
El impacto de la migración en el crecimiento poblacional del Estado de México / A. MEJÍA MODESTO et al.

Tabla 6c: Estado de México. Diferencia porcentual de población absoluta de 2015 a 2010

\begin{tabular}{|c|c|}
\hline Municipio & Diferencia porcentual \\
\hline Mexicaltzingo & 9.26 \\
\hline Aculco & 9.38 \\
\hline Tejupilco & 9.46 \\
\hline Tepetlaoxtoc & 9.79 \\
\hline Hueypoxtla & 9.83 \\
\hline Xalatlaco & 10.08 \\
\hline Coatepec Harinas & 10.29 \\
\hline Villa de Allende & 10.34 \\
\hline Texcaltitlán & 10.44 \\
\hline San Felipe del Progreso & 10.50 \\
\hline Huixquilucan & 10.61 \\
\hline Chimalhuacán & 10.64 \\
\hline Valle de Chalco Solidaridad & 10.77 \\
\hline Tenango del Valle & 10.79 \\
\hline Chalco & 10.82 \\
\hline Villa Victoria & 10.85 \\
\hline Atenco & 10.93 \\
\hline Ayapango & 11.27 \\
\hline Chiautla & 11.33 \\
\hline Xonacatlán & 11.47 \\
\hline Acolman & 11.68 \\
\hline Atlautla & 11.86 \\
\hline Nicolás Romero & 11.87 \\
\hline Chiconcuac & 11.94 \\
\hline Zinacantepec & 12.62 \\
\hline Soyaniquilpan de Juárez & 12.65 \\
\hline Villa Guerrero & 13.23 \\
\hline Isidro Fabela & 13.76 \\
\hline Melchor Ocampo & 13.76 \\
\hline Tultepec & 14.15 \\
\hline Atizapán & 15.30 \\
\hline Temoaya & 15.36 \\
\hline $\mathrm{La} \mathrm{Paz}$ & 15.71 \\
\hline Temamatla & 15.87 \\
\hline Chicoloapan & 16.60 \\
\hline Tezoyuca & 17.43 \\
\hline Tenango del Aire & 17.89 \\
\hline Cocotitlán & 18.71 \\
\hline Almoloya de Juárez & 19.36 \\
\hline Calimaya & 20.29 \\
\hline
\end{tabular}

Fuente: elaboración propia con datos del INEGI. 
Tabla 6d: Estado de México. Diferencia porcentual de población absoluta de 2015 a 2010

\begin{tabular}{lr}
\hline Municipio & Diferencia porcentual \\
\hline Chapultepec & 21.58 \\
Tecámac & 22.34 \\
San Antonio la Isla & 22.92 \\
Zumpango & 24.69 \\
Nextlalpan & 25.16 \\
Huehuetoca & 28.46 \\
\hline
\end{tabular}

Fuente: elaboración propia con datos del INEGI.

De hecho, los recién egresados de las universidades forman ese "nuevo ejército industrial de reserva" que menciona Beck (1997). Así también los posgrados son cada vez más requeridos y en ocasiones también insuficientes. Los riesgos del tipo manufacturado, es decir, los riesgos que resultan del desarrollo de la tecnología, que sustituye el trabajo con nuevos robots, nuevas microcomputadoras, con nuevos programas y nuevas aplicaciones, han cambiado las dinámicas laborales. El más común el teléfono inteligente, el cual ha sido la herramienta de trabajo que extiende la jornada laboral tanto en horario como en días. De hecho nunca nos despegamos del trabajo, tenemos un vínculo virtual que si nos atrevemos a romper podríamos también favorecer la pérdida de nuestro empleo, con todo lo que esto implica. Por ejemplo, tener que optar por un empleo diferente, un empleo precario, informal, de medio tiempo.

\section{REFERENCIAS BIBLIOGRÁFICAS}

Beck, Ulrich, 1997, "La reinvención de la política: hacia una teoría de la modernización reflexiva", en Beck U. A. Giddens y Lash, S., Modernización reflexiva política, tradición y estética en el orden social moderno, Alianza Universidad, España.

Bustamante, M. y otros, 1982, La salud Pública en México 1959-1982, Secretaría de Salubridad y Asistencia México.

CONAPO, 2016, Índice de marginación por entidad federativa y municipio 2015, disponible en https://www.gob.mx/conapo/documentos/indice-de-marginacionpor-entidad-federativa-y-municipio-2015.

Humboldt, A., 2002, Ensayos político sobre el reino de la Nueva España, colección Sepan cuantos num. 39. Editorial Porrúa, México 
INEGI, 2016a, Censo de Población y Vivienda 2010, disponible en www.inegi. org.mx

INEGI, 2016b, Encuesta Intercensal de Población 2015, disponible en www.inegi.org.mx

Küng H., 2000, Una ética mundial para la economía y la política. Fondo de Cultura Económica, México.

McCaa, R., 2001, "El poblamiento de México: de sus orígenes a la Revolución”, en Gómez de León J. y Rabell, C., La población de México. Tendencias y Perspectivas sociodemográficas hacia el siglo XXI. CONAPO, FCE, México.

Ordorica, Manuel y Lezama, J. L., 1993, “Consecuencias demográficas de la Revolución Mexicana”, en El Poblamiento de México, t. 4 México en el siglo XX. CONAPO, México.

PNUD, 2015, Índice de Desarrollo Humano para las entidades federativas, México 2015, disponible en http://www.mx.undp.org/content/dam/mexico/docs/Publicaciones/PublicacionesReduccionPobreza/InformesDesarrolloHumano/PNUD boletinIDH.pdf

\section{RESUMEN CURRICULAR DE LOS AUTORES}

\section{Alfonso Mejía Modesto}

Doctor en Ciencias Políticas y Sociales por la UNAM. Ha trabajado en el CONAPO y ha sido consultor para diversas instituciones como el IMSS y el FNUAP de la ONU. Ha sido profesor de asignatura en la ENAH, la UAEH, el ITAM y la UNAM. Actualmente es profesor e investigador de tiempo completo en el Centro de Investigación y Estudios Avanzados de la Población de la Universidad Autónoma del Estado de México. Temas de investigación principales: Dinámica demográfica, salud sexual y reproductiva, políticas de población, jóvenes y sociedad del riesgo.

Dirección electrónica: mejiaalfonso@yahoo.com.mx

\section{María Viridiana Sosa Márquez}

Doctora en Estudios de Población y Maestra en Demografía por El Colegio de México. Actualmente se desempeña como profesora investigadora en el Centro de Investigación y Estudios Avanzados de la Población de la Universidad Autónoma del Estado de México. Su actividad de investigación se centra en temas de nupcialidad, familia, trabajo y migración. Entre sus publicaciones destacan: el artículo Las redes sociales en la migración de retorno (2018); y los capítulos en libro Una mirada a los compromisos normativos sobre derechos laborales relacionados con el trabajo domés- 
tico no remunerado de las mujeres (2018); y Familia y maternidad en la dinámica migratoria en las mujeres mexicanas (2018).

Dirección electrónica: mvsosam@uaemex.mx

Eduardo Andrés Sandoval Forero

Antropólogo, Maestro en Estudios Latinoamericanos, Doctor en Sociología por la Universidad Nacional Autónoma de México (UNAM). Miembro del Sistema Nacional de Investigadores de México desde 1995 (Nivel II). Profesor invitado de universidades de Estados Unidos, América del Sur, España e Italia. Es profesor del curso Migración y codesarrollo en la Cátedra UNESCO, del posgrado de Estudios para la Paz y el Desarrollo, en la Universitat Jaume I, España. Autor de varios artículos, capítulos y libros sobre migración, diversidad cultural y grupos étnicos. Líder del Cuerpo Académico en Migración Interna e Internacional del Centro de Investigación y Estudios Avanzados de la Población de la Universidad Autónoma del Estado de México. Su mas reciente libro es Educación para la paz integral. Memoria, Interculturalidad y decolonialdad.

Dirección electrónica: forerosandoval@gmail.com

Artículo recibido el 16 de febrero de 2017 y aprobado el 4 de mayo de 2018 . 